\title{
Validation of the Adherence Determinants Questionnaire scale among women with breast and cervical cancer ${ }^{1}$
}

\author{
Paula Renata Amorim Lessa ${ }^{2}$ \\ Samila Gomes Ribeiro ${ }^{2}$ \\ Priscila de Souza Aquino ${ }^{3}$ \\ Paulo Cesar de Almeida ${ }^{4}$ \\ Ana Karina Bezerra Pinheiro ${ }^{5}$
}

Objectives: the aim was to translate and culturally adapt the Adherence Determinants Questionnaire scale for the Portuguese language in the Brazilian context, and to check its reliability and validity to analyze the elements of the adherence of patients to the clinical treatment for breast and cervical cancer. Method: this was a methodological study, carried out in two oncology reference centers. The sample consisted of 198 participants, with 152 being treated for breast cancer and 46 being treated for cervical cancer. The content validation was performed by a committee of experts. The construct validation was demonstrated through factor analysis and the reliability was analyzed using Cronbach's alpha. Results: the committee of experts made the necessary adjustments so that the scale was adapted to the Brazilian context. The factor analysis suggested a reduction from seven to five factors and the maintenance of 38 items similar to those of the original scale. The reliability, investigated through Cronbach's alpha, was .829, showing high internal consistency. Conclusion: it was concluded that the Brazilian version of the Adherence Determinants Questionnaire scale is a valid and reliable instrument that is able to measure the elements of adherence to the treatment for breast and cervical cancer.

Descriptors: Patient Compliance; Breast Neoplasms; Uterine Cervix Neoplasms; Validation Studies; Oncologic Nursing.

\footnotetext{
${ }^{1}$ Paper extracted from master's thesis "Translation, adaptation and validation of the scale Adherence Determinants Questionnaire for use in Brazil", presented to Universidade Federal do Ceará, Fortaleza, CE, Brazil.

2 Doctoral student, Universidade Federal do Ceará, Fortaleza, CE, Brazil. Scholarship holder from Coordenação de Aperfeiçoamento de Pessoal de Nível Superior (CAPES), Brazil.

3 PhD, Assistant Professor, Faculdade de Enfermagem, Universidade Federal do Ceará, Fortaleza, CE, Brazil.

${ }^{4} \mathrm{PhD}$, Associate Professor, Faculdade de Enfermagem, Universidade Estadual do Ceará, Fortaleza, CE, Brazil.

${ }^{5} \mathrm{PhD}$, Associate Professor, Faculdade de Enfermagem, Universidade Federal do Ceará, Fortaleza, CE, Brazil.
}

Corresponding Author:

Paula Renata Amorim Lessa

Universidade Federal do Ceará. Departamento de Enfermagem

Rua Alexandre Baraúna, 1115

Bairro: Rodolfo Teófilo

CEP: 60430-160, Fortaleza, CE, Brasil

E-mail: paularenatal@yahoo.com.br
Copyright $\odot 2015$ Revista Latino-Americana de Enfermagem This is an Open Access article distributed under the terms of the Creative Commons Attribution Non-Commercial License (CC BY-NC).

This license lets others distribute, remix, tweak, and build upon your work non-commercially, and although their new works must also acknowledge you and be non-commercial, they don't have to license their derivative works on the same terms. 


\section{Introduction}

In the female population, it is observed that breast cancer has the highest global prevalence and cervical cancer occupies the third position. In Brazil, following the worldwide trends, breast cancer is the pioneer in the statistics, followed by cervical cancer, which occupies the second position ${ }^{(1)}$. Despite the chances of treatment of cervical and breast cancer, when detected early through the Pap smear examination and mammogram, respectively, and the favorable possibilities of a cure, the diagnosis of breast or cervical cancer has several repercussions in the lives of women, as well as their family members. Several kinds of coping and negative responses therefore arise, mainly related to the fear of dying ${ }^{(2-3)}$. There are various recommendations and treatment options for breast and cervical cancer. The treatment methods for cervical and breast cancer that are similar, such as chemotherapy and radiotherapy, cause diverse negative effects, such as nausea, cognitive dysfunction, induced menopause, decreased vaginal lubrication and dyspareunia, leading to a significant reduction in sexual desire and the quality of daily life(4-6). Furthermore, the recommended treatments for cervical cancer and breast cancer are highly aggressive and significantly transform the social and personal relationships of these women. For this reason many women do not adhere to the proposed treatment when diagnosed with these cancers.

Adherence to the treatment regimen appears as a complex issue, including the definition of the term, the difficulty of coping and even its measurement, since adherence can be operationalized in different ways. In general, adherence is a dynamic and multifactorial process that involves co-participation among the triad: user, health professionals and social support network ${ }^{(7)}$.

All forms of measurement require a specific protocol that demands competence and interpretation of the health professional to evaluate the historical context of each patient ${ }^{(7)}$. Therefore, the Adherence Determinants Questionnaire (ADQ) scale was developed by American researchers, which aims to evaluate the elements of self-adherence of patients to the clinical treatment for cancer, taking into consideration a set of cognitive and motivational skills, as well as social and behavioral variables, making it a multifactorial instrument ${ }^{(8)}$. Accordingly, adherence to treatment is related to multiple factors, such as social, economic and cultural factors, factors related to health systems, services and professional, and factors related to the disease, the treatment and the sick person. These categories positively or negatively influence the act of the patient adhering or not to the treatment ${ }^{(9)}$. Such constructs are covered in the ADQ scale.

It should be noted that the validation of the original scale was performed with groups of primary, secondary and tertiary prevention, including women treated for cervical cancer. Given the prevalence of cervical and breast cancer in Brazil, it was decided to perform the validation for this specific population, which does not prevent its application with other population groups, provided similar contextual and cultural aspects are considered.

In Brazil, there are no known specific instruments, whether constructed or adapted for the Brazilian language, to evaluate the reasons for adherence or not to cancer treatment in a comprehensive manner, as in the ADQ scale. Therefore, the use of an instrument that can facilitate the identification of the main reasons for nonadherence to cancer treatment, specifically cervical and breast cancer, which may favor systematized care and provide a better approach of the healthcare professional to the clients affected by this disease, should be considered as an important strategy for improving the care and quality of life of women undergoing treatment for these cancers. Given the lack of measurement instruments for adherence to the treatment of breast and cervical cancer, this study aimed to translate, adapt and validate the Adherence Determinants Questionnaire scale, according to the Brazilian context.

\section{Method}

This was a methodological study of the adaptation and validation of the Adherence Determinants Questionnaire scale instrument for the Portuguese language, in the Brazilian context. This scale has not been validated into any other languages. The study was conducted in two phases: 1 ) translation and adaptation of the ADQ scale and 2) evaluation of the psychometric properties. Considering the various translation and cultural adaptation methods, a methodological framework of cultural adaptation that consisted of five steps was used, these being: 1 . initial translation, 2 . synthesis of translations, 3. translation back to the original language (back-translation), 4. review by a committee of experts and 5. pre-test $^{(10)}$.

The first step, initial translation, was performed by two individuals fluent in the language of the original scale that independently translated it into Portuguese: 
one translator (T1) that was not from the health field (professor of the House of British Culture of the Federal University of Ceará) and the other (T2) that was a health professional (Master's student in public health), with fluency in English(10). In the synthesis of translations step, the two translated versions ( $\mathrm{T} 1$ and $\mathrm{T} 2$ ) were pooled and synthesized into a single final instrument (T12), with the participation of the main author of this study, in order to minimize the possibilities of typical translation errors, such as omission or additions of words that could change the real meaning(10). In step III, the back-translation to the original language, two other native English speaking translators with knowledge of Portuguese, who did not know the original version of the scale, independently performed new translations (BT1 and BT2) of the T12 version produced in the previous step back into the original language. This is a validity verification process that allows the inconsistencies and conceptual errors made during the process of initial translation and synthesis of the translations to be checked.

In step IV, review by the committee of experts, five judges were selected according to pre-established criteria that considered their scientific production, practical experience with the issue of adherence to breast cancer and cervical cancer treatment and their experience with the translation, adaptation and validation of instruments, including a specialist linguistic nurse. This step was carried out in groups with the judges, in person rather than through written or electronic means, as this saves time. This method enabled the exchange of experiences among the participants of the group, highlighting the discussions and the material produced. The role of the expert committee was to consolidate all the versions, including the original instrument and the translated versions ( $\mathrm{T} 1, \mathrm{~T} 2, \mathrm{~T} 12, \mathrm{BT} 1$ and $\mathrm{BT} 2)$ for the purpose of developing the pre-final version for field testing. The criteria assessed by the committee of judges were: analysis of semantic, idiomatic, functional and conceptual equivalence.

The final stage of the translation and cultural adaptation was the pre-test, the purpose of which was to verify the comprehension of the scale by the target public. The Brazilian version of the Adherence Determinants Questionnaire- (ADQ-BV) scale was applied with a population of 30 subjects and the comprehension of it was verified by the target public, ensuring that the adapted version maintained its equivalence in an application situation. The scale application time was also registered so that the women participating in the study could be given this information.
The second stage of the study was to analyze the psychometric properties, this being necessary to make sure the adapted instrument has the same properties as the original scale. This verification was through a process of validation and reliability. The content validation was performed by the committee of experts and the clarity and comprehension of the items was discussed, as well as the relevance of each item in the scale. The construct validation was performed after application of the scale with the target public, through exploratory factor analysis. Factor analysis shows that the instrument is actually measuring the factors, and the relationship of each of the scale items with their respective factors. It should be noted that, prior to the use of factor analysis, it is necessary to test some assumptions. The KaiserMeyer-Olkim (KMO) measure of sampling adequacy and Bartlett's sphericity test were used to analyze the viability of the factor analysis. In factor analysis, a positive or negative factor loading of at least 0.3 is considered to demonstrate the maintenance of the relationship between the item and the particular factor ${ }^{(11)}$. After extraction of the factors, their rotation was performed. Orthogonal varimax rotation was selected, as it adds fewer variables within each factor, facilitating the data interpretation.

Regarding the reliability, the test chosen to analyze the homogeneity of the ADQ-BV scale was the Cronbach's alpha measure of internal consistency precision, which is the most common measure used for reliability ${ }^{(12)}$. The Cronbach's alpha value can vary between 0 and 1 , with values greater than .7 being considered acceptable. The Cronbach's alpha measures the unidimensionality of an instrument. As the ADQ scale presents several subcomponents (domains), the Cronbach's alpha was calculated separately for each domain, as theoretically there are several constructs in question(12). In addition, the reverse items were adjusted for the Cronbach's alpha calculation.

The ADQ scale has 38 statements, with a Likert type response scale ranging from 1 to 5, from strongly agree, agree, neither agree nor disagree, disagree and strongly disagree. The Cronbach's alpha value of the total scale in the English language was 0.76, presenting good reliability. The categories analyzed in the instrument are as follows: (1) perceptions of interpersonal care, (2) beliefs about disease susceptibility, (3) beliefs about the severity of the disease, (4) assessments of the costs and benefits of treatment adherence perceived by the patient (5) subjective perception of social standards to adhere, (6) intention to adhere and (7) perceptions of available support and absence of barriers to adherence( ${ }^{(8)}$. 
The pre-test step (5) and construct validity were developed in two reference centers for oncology treatment in the state of Ceará, Northeastern Brazil. The population for the validation step consisted of women diagnosed with malignant changes of cervical or breast cancer, undergoing specialized treatment (chemotherapy or radiotherapy).

The sample was calculated considering the recommendation of between 5 and 10 participants per variable(11). The QDA scale consists of 38 items. Thus, by performing a simple calculation, multiplying thirty eight by five, the number of 190 was obtained. The study included 198 participants, 152 being treated for breast cancer and 46 being treated for cervical cancer. As following inclusion criteria were defined: women being treated for breast cancer or cervical cancer. The discontinuation criteria considered were: ceasing to participate in the study after the initiation of the data collection, or death during the data collection period.

Data collection took place from May to July 2012, through the application of the ADQ-BV scale and a form to collect sociodemographic data. The invitation for participation in the study was given verbally, in the waiting room, while the women waited for the start of chemotherapy or radiotherapy. After reading the Informed Consent (IC) form and giving their agreement, the women were taken to a room provided by the service for this purpose. The Statistical Package for the Social Sciences (SPSS) version 19.0 was used for the analysis of the construct validation data, through factor analysis and reliability.

The study was approved by the Research Ethics Committee (CEP) of the Federal University of Ceará, with authorization No. 3/12, and compliance with the standards for research involving human subjects was ensured, as recommended by Resolution No. 466/2012 of the National Health Council of Brazil. In addition, contact was previously established with the main author of the scale by means of electronic mail, who authorized the development of the study.

\section{Results}

The cross-cultural adaptation configures a rigorous process consisting of several steps in order to produce an instrument equivalent to the original instrument in terms of the measurement of the construct, but that has particularities specific to the context in which the scale is to be applied. Comparing the T1 and T2 translations, in general, no significant differences were found between the two versions. However, it was observed that in the T2 version, translated by a health professional, the term "plano de tratamento" was used for the expression "treatment plan". The T12 version underwent several changes after the evaluation by the expert committee, with the following highlighted: 1) the redundancy of the phrase "Os médicos e outros profissionais da saúde" was discussed. However, all five members of the committee agreed with the idea that the doctor is the main figure in the cancer treatment, a concept embedded the in Brazilian culture, and should therefore be translated independently as in the original scale; the personal pronoun "eu" was included in various statements. The justification for this addition was the fact that the word "eu" relates to a concept of control of the treatment, making the woman subject active and responsible for her health/disease process versus the treatment and seeking her self-care, as decided by the members of the expert committee.

At the end of the evaluation by the expert committee the scale maintained 38 items, as in the original scale. Thus, as the present study was a translation and adaptation, it was decided to consider the expert committee stage in which all equivalences were verified (conceptual, experiential, functional and idiomatic) as the content validation. In addition, it should be noted that extensive work of construction and content analysis was already done by the authors of the original version of the scale.

The pre-test step was conducted with 22 women diagnosed with breast cancer and 8 women with cervical cancer. The minimum education of the pretest participants was 1 year and the maximum 12 years. Regarding age, the minimum was 45 years and the maximum 79 years. In this step, the researcher read, together with all the participants, each item of the scale, as well as the introductory guidance. All of the women reported having comprehended all the statements, therefore there was no need to modify the items of the scale in the pre-final version.

The construct validity and reliability steps were carried out with a heterogeneous sample, with regard to the type of cancer (breast and cervical). The sociodemographic characteristics of the women with breast cancer and cervical cancer were similar: predominant age group between 40 and 65 years, the majority with the presence of a companion, low levels of education and income, and few professional qualifications. For the construct validity through factor analysis, the value found for the KMO, in this study, was .696 and the sphericity test showed statistical significance $(p=.001)$. 
These results revealed that factor analysis was suitable for the analysis of the QDA scale. The use of the scree plot was chosen, indicating how many factors should be extracted, from the graph that indicates the number of components above the inflection point.

As shown by the graph below, a curve with a difficult interpretation was verified, as it begins to have a tail after four factors, accentuating after the fifth factor. Therefore, after critical evaluation and initial comparison with the original scale, which consists of seven domains, the extraction of five factors was defined.

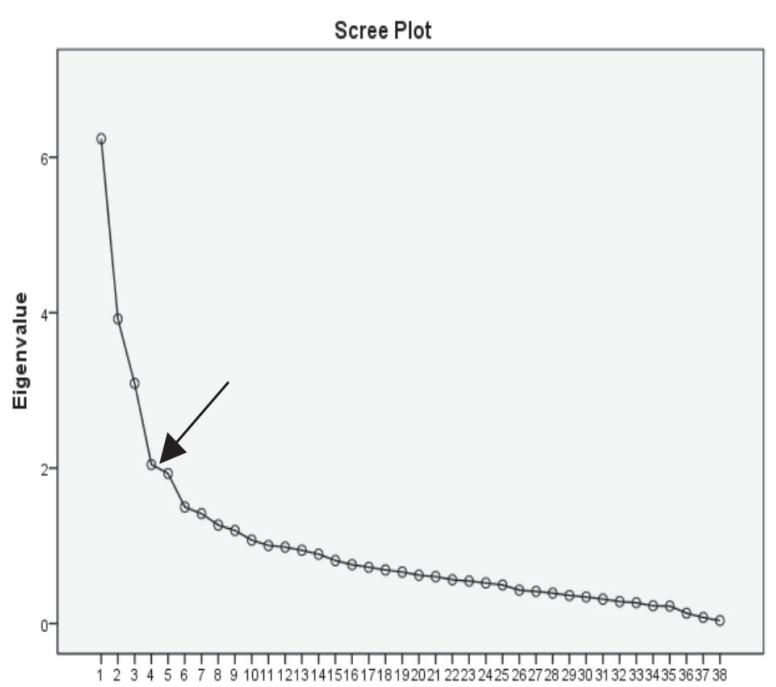

Figure 1 - Scree plot. Fortaleza, CE, Brazil, May/July 2012

The interpretation of the factors can be further comprehended through the rotation. The rotation indicates what variables relate more strongly with each factor, through the factor loading. According to Table 1, the items were distributed in five factors. For the variables that presented loadings in more than one factor, the factor with the highest loading value was considered. It was also confirmed that all the variables showed a value higher than 0.3 , with it not being necessary to exclude any.

Table 2 presents the internal consistency analysis data, in which, analyzed in detail, the correlation is present for each item with the total scale, as well as the alpha value if the item was deleted. It can be observed that the alpha value did not undergo major changes if any of the items were removed from the scale.

The total Cronbach's alpha value of the scale found was .829, indicating that the instrument shows good internal consistency. The Cronbach's alpha of the original scale was .76. The Cronbach's alpha values for each domain of the scale, were calculated separately, ranging from .639 to .844 .
Table 1 - Correlation matrix between the items and domains of the ADQ-BV, according to factorial analysis by principle components and varimax rotation. Fortaleza, CE, Brazil, 2012

\begin{tabular}{|c|c|c|c|c|c|}
\hline & \multicolumn{5}{|c|}{ Components } \\
\hline & 1 & 2 & 3 & 4 & 5 \\
\hline Item 3 & .815 & & & & \\
\hline Item 5 & .777 & & & & \\
\hline Item 2 & .766 & & & & \\
\hline Item 7 & .674 & & & & \\
\hline Item 6 & .653 & & & & \\
\hline Item 1 & .643 & & & & \\
\hline Item 4 & .605 & & & & \\
\hline Item 8 & .568 & & & & \\
\hline Item 28 & & .813 & & & \\
\hline Item 26 & & .777 & & & \\
\hline Item 30 & & .756 & & & \\
\hline Item 27 & & .737 & & & \\
\hline Item 29 & & .671 & & & \\
\hline Item 25 & & .604 & & & \\
\hline Item 22 & & & .734 & & \\
\hline Item 24 & & & .731 & & \\
\hline Item 23 & & & .696 & & \\
\hline Item 21 & & & .608 & & \\
\hline Item 13 & & & .574 & .313 & \\
\hline Item 16 & & & .433 & & \\
\hline Item 20 & & & -.408 & -.345 & \\
\hline Item 15 & & & .381 & & \\
\hline Item 33 & & & & .802 & \\
\hline Item 31 & & & & .799 & \\
\hline Item 34 & & & & .597 & \\
\hline Item 14 & & & & .526 & \\
\hline Item 11 & & & .356 & .507 & \\
\hline Item 32 & & & & .498 & \\
\hline Item 12 & & & .380 & .420 & \\
\hline Item 9 & & & & .339 & \\
\hline Item 36 & & & & & .626 \\
\hline Item 37 & .343 & & & & .592 \\
\hline Item 19 & & & & & -.573 \\
\hline Item 35 & & & & & .550 \\
\hline Item 18 & & & & & -.518 \\
\hline Item 38 & & & & & .409 \\
\hline Item 17 & & & & & -.385 \\
\hline Item 10 & & & & & .357 \\
\hline
\end{tabular}


Table 2 - Mean, variance, correlation item/total and Cronbach's alpha for the ADQ-BV. Fortaleza, CE, Brazil, 2012

\begin{tabular}{|c|c|c|c|c|}
\hline & $\begin{array}{l}\text { Mean of } \\
\text { the scale if } \\
\text { the item is } \\
\text { deleted }\end{array}$ & $\begin{array}{c}\text { Variance of } \\
\text { the scale if } \\
\text { the item is } \\
\text { deleted }\end{array}$ & $\begin{array}{l}\text { Correlation } \\
\text { item/total }\end{array}$ & $\begin{array}{l}\text { Cronbach's } \\
\text { alpha if } \\
\text { the item is } \\
\text { deleted }\end{array}$ \\
\hline Item1 & 153.90 & 192.191 & .297 & .827 \\
\hline Item 2 & 153.36 & 192.097 & .363 & .824 \\
\hline Item 3 & 153.32 & 188.453 & .540 & .819 \\
\hline Item 4 & 154.10 & 191.750 & .290 & .827 \\
\hline Item 5 & 153.39 & 191.594 & .422 & .822 \\
\hline Item 6 & 153.22 & 192.931 & .434 & .822 \\
\hline Item 7 & 153.05 & 196.756 & .315 & .826 \\
\hline Item 8 & 153.56 & 194.751 & .303 & .826 \\
\hline Item 9 & 153.20 & 200.242 & .175 & .829 \\
\hline Item 10 & 154.11 & 192.568 & .283 & .827 \\
\hline Item 11 & 152.98 & 193.031 & .442 & .822 \\
\hline Item 12 & 152.72 & 197.708 & .381 & .825 \\
\hline Item 13 & 152.80 & 197.186 & .431 & .824 \\
\hline Item 14 & 152.83 & 196.910 & .467 & .824 \\
\hline Item 15 & 153.62 & 197.252 & .189 & .830 \\
\hline Item 16 & 153.43 & 189.519 & .435 & .821 \\
\hline Item 17 & 153.85 & 194.428 & .236 & .829 \\
\hline Item 18 & 154.34 & 199.026 & .135 & .832 \\
\hline Item 19 & 154.75 & 190.568 & .317 & .826 \\
\hline Item 20 & 153.46 & 190.753 & .438 & .822 \\
\hline Item 21 & 153.95 & 193.757 & .319 & .825 \\
\hline Item 22 & 152.84 & 195.573 & .375 & .824 \\
\hline Item 23 & 153.82 & 194.517 & .286 & .826 \\
\hline Item 24 & 153.26 & 195.053 & .364 & .824 \\
\hline Item 25 & 152.62 & 202.473 & .156 & .829 \\
\hline Item 26 & 152.72 & 199.329 & .272 & .827 \\
\hline Item 27 & 152.73 & 200.637 & .210 & .828 \\
\hline Item 28 & 152.85 & 198.978 & .253 & .827 \\
\hline Item 29 & 152.67 & 201.054 & .231 & .828 \\
\hline Item 30 & 152.76 & 197.527 & .361 & .825 \\
\hline Item 31 & 152.59 & 200.561 & .456 & .826 \\
\hline Item 32 & 152.89 & 198.316 & .271 & .827 \\
\hline Item 33 & 152.58 & 201.681 & .363 & .827 \\
\hline Item 34 & 152.80 & 202.242 & .123 & .830 \\
\hline Item 35 & 154.09 & 193.116 & .265 & .828 \\
\hline Item 36 & 154.34 & 188.739 & .373 & .824 \\
\hline Item 37 & 153.73 & 188.506 & .468 & .820 \\
\hline Item 38 & 153.13 & 199.137 & .268 & .827 \\
\hline
\end{tabular}

\section{Discussion}

In the initial steps of the translation, synthesis of the translations and back-translation the choice of translators should be performed very carefully, in order to minimize errors and provide a translation coherent with the context in which scale is to be applied. Therefore, the choice of one translator who was a health professional and the other who was not in this thematic area was essential for the production of a version contextualized in the Brazilian quotidian.

In this context, the choice of the participants for the expert committee should also be carried out carefully, as a diversification of knowledge is essential for the functionality and dynamism of the step, as well as for the construction of the pre-final version. The heterogeneity of the group significantly contributed to the discussions about the best grammatical, cultural and conceptual form of the scale items. It is emphasized that the fact that this step was performed in person allowed richer discussions.

Regarding the construct validity, the factor analysis identified the extraction of five factors, unlike the original scale which measures seven factors.

In the original scale items 13, 15 and 16 belonging to domain II - Perceived Usefulness (benefits/costs and efficacy) and are intrinsically related to the domain that deals with perceived susceptibility, since the three displaced items depict the vulnerability to cancer to which women are exposed, following or not the treatment.

In addition, items 9, 11, 12 and 14 were displaced, after the factor analysis, to the Intention domain. Domain II, which depicts the costs and benefits of adherence to treatment, covers the idea contained in the Intention domain, since intention can be seen as an important behavioral action in studies of health behaviors that could translate into preventive actions ${ }^{(13)}$. Thus, from the reflection about the benefits and difficulties of the cancer treatment, the decision is taken to adhere or not to the treatment, highlighting that the construct measured in domain II can be reorganized into the Intention domain without prejudicing the measurement of the construct.

Domain III, Perceived Severity, was almost completely inserted into the Social Support Network domain. One possible explanation may be related to the fact that, from the recognition of the severity of the disease, the individual might or might not need the support social networks. It is known that the belief about the disease severity can influence the adherence of the person to the treatment ${ }^{(14)}$. 
Furthermore, the realities in which the scales were validated differ in various aspects, especially with regard to the education of the participants. The women in the study often reported not having a great knowledge about the treatment to which they were being subjected, nor the type and aggressiveness of the cancer they had. Therefore, the Cost/Benefits and Perceived Severity domains can be interconnected with other subcomponents of the scale, as revealed in the factor analysis.

Reporting the results of the factor analysis, it was observed that no item presented a factor loading less than 0.3 , as recommended(11). Thus, no items needed to be excluded, showing good correlation between the scale items and the constructs to be measured.

In terms of the reliability analysis, Cronbach's alpha resulted in values that denoted good reliability of the instrument, with the overall value of the scale being .829 .

The original scale obtained a Cronbach's alpha value slightly below the value of the translated scale with 0.76 . This can be explained by the changes that were made after the factor analysis, with the exclusion of two domains.

However, it is known that, when dealing with instruments that possess various subcomponents, such as the ADQ scale, the separate analysis of the domains reveals greater precision of the instrument, since Cronbach's alpha measures the unidimensionality of one construct, with values greater than .6 being acceptable ${ }^{(11)}$.

The Cronbach's alpha values of the ADQ scale varied between .639 and .844, revealing that the Brazilian version of the ADQ scale presents high internal consistency and can be considered to be a reliable instrument.

However, it is known that adherence is not an easy to measure attribute and one should always try to identify the main difficulties in this process faced by people who experience treatment for chronic diseases, including cancer, in order to minimize them, improving their quality of $\operatorname{life}^{(7)}$. Thus, the ADQ scale seeks to address the different constructs that involve adherence, comprehending the complexity involved in this issue.

\section{Conclusion}

Regarding the evaluation of the psychometric properties, the Brazilian version of the ADQ scale resulted in 38 items similar to those of the original scale. In contrast, two domains were removed from the original scale, producing five domains in the Brazilian version, resulting from the factor analysis. This change suggests that researchers who work with the adaptation and validation of instruments should carefully evaluate the life context to which scale is to be applied, in order to guide decisions such as the exclusion of items and domains, so that they do not merely transcribe, without critical thinking, the processes of validation performed in the original instrument.

It should also be added that the domains of the scale and the total scale showed high indices of reliability, through the Cronbach's alpha values, which ranged from .639 to .844 , resulting in the total scale value of .829 . It was therefore concluded that the ADQ-BV scale is a valid and reliable instrument that is able to measure the elements of adherence to the treatment for cancer. In addition, the instrument highlights elements that can be positively reinforced and serve as support in order to improve the adherence to treatment for cervical and breast cancer.

Finally, it is believed that this study contributes with the publication of a reliable scale that is able to measure the elements of adherence to the treatment for cervical and breast cancer. The study also enables nurses, other health professionals and managers to rethink their health practices, directing their interventions in a participatory manner with the client and family members, considering them as a reference in their attitudes, in order to contribute to better quality of life and coping with these cancers that are still very prevalent in the quotidian of Brazilian women.

\section{References}

1. Instituto Nacional do Câncer José Alencar Gomes da Silva [Internet]. Estimativa 2014. Incidência de câncer no Brasil [acesso 2 jan 2014]. Disponível em: http:// www2.inca.gov.br/wps/wcm/connect/tiposdecancer/ site/home/mama

2. Nerone $V$, Trincaus MR. Reações emocionais e sentimentos experienciados pelas mulheres com câncer de colo uterino. Rev Salus-Guarapuava. 2007;1(2):147-55.

3. Oliveira MS, Fernandes AFC, Galvão MTG. Mulheres vivenciando o adoecer em face do câncer cérvicouterino. Acta Paul Enferm. 2005;18(2):150-5.

4. Salimena AMO, Souza IE. O sentido da sexualidade de mulheres submetidas à histerectomia: uma contribuição da enfermagem para a integralidade da assistência ginecológica. Esc Anna Nery. 2008;12(4):637-44. 
5. Santos DB, Vieira EM. Imagem corporal de mulheres com câncer de mama: uma revisão sistemática da literatura. Ciênc Saúde Coletiva. 2011;16(5):2511-22.

6. Gonçalves LLC, Lima AV, Brito ES, Oliveira MM, Albuquerque $L$, Oliveira $R$, et al. Fatores de risco para câncer de mama em mulheres assistidas em ambulatório de oncologia. Rev Enferm UERJ. 2010;18(3):468-72.

7. Leite SN, Vasconcellos MPC. Adherence to prescribed therapy: points for concepts and presuppositions discussion. Ciênc Saúde Coletiva. 2003;8(3):775-82.

8. Dimatteo R, Hays RD, Gritz Er, Bastani R, Crane L, Elashoff $R$, et al. Patient Adherence to Cancer Control Regimens: Scale Development and Initial Validation. Psychol Assess. 1993;5(1):102-12.

9. Souza BF, Pires FH, Dewulf NLS, Inocenti A, Silva AEBC, Miasso AI. Patients on chemotherapy: depression and adherence to treatment. Rev Esc Enferm USP. 2013;47(1):61-8.

10. Beaton D, Bombardier C, Guillemin F, Ferraz MB. Recommendations for the cross-cultural adaptation of health status measures. [Internet]. Califórnia: American Academy of Orthopaedic Surgeons and Institute for Work \& Health; 2007. [acesso 2 jun 2012]. Disponível em: http://www.dash.iwh.on.ca

11. Pasquali L. Psicometria. Rev Esc Enferm USP. 2009;43(Esp): 992-9.

12. Cronbach LJ. Coefficient alpha and the internal structure of tests. Psychometrika. 1951;16:297-334.

13. Cavalcanti APR, Dias MR, Costa MJC. Psicologia e nutrição: predizendo a intenção comportamental de aderir a dietas de redução de peso entre obesos de baixa renda. Estudos Psicol. 2005;10(1):121-9.

14. Cardoso L, Miasso AI, Galera SAF, Maia BM, Esteves RF. Adherence level and knowledge about psychopharmacological treatment among patients discharged from psychiatric internment. Rev. Latino-Am. Enfermagem. 2011;19(5):1146-54. 